\title{
Towards a Fast Evaluation of Environmental Impacts
}

\author{
Daniele Cerri ${ }^{1}$, Marco Taisch $^{1}$, Sergio Terzi $^{2}$, and Simone Parrotta ${ }^{3}$ \\ ${ }^{1}$ Politecnico di Milano, Department of Management, Economics and Industrial Engineering, \\ Piazza Leonardo da Vinci 32, 20133, Milano, Italy \\ \{daniele.cerri, marco.taisch\}@polimi.it \\ ${ }^{2}$ Università degli Studi di Bergamo, Department of Industrial Engineering, Viale Marconi 5, \\ 24044, Dalmine (Bergamo), Italy \\ sergio.terzi@unibg.it \\ ${ }^{3}$ Holonix S.R.L., Corso Italia 8, 20821 Meda (Monza Brianza) \\ simone.parrotta@holonix.it
}

\begin{abstract}
Full LCA is a well-known methodology which can help decisionmakers to select the product or process that results in the least impact to the environment. However performing a Full LCA is resource and time intensive. Therefore different simplified LCA methods are developed in literature. This paper would develop another simplified LCA tool, driven by the extreme ease of use for all the people that don't know in depth environmental issues or that haven't time / data to deepen these topics. This tool can be very useful to the designers. They should be evaluate environmental impacts of something doesn't exist and it can help them to evaluate rapidly the more "green" product.
\end{abstract}

Keywords: LCA, Life Cycle Assessment.

\section{$1 \quad$ Introduction}

Full LCA is a very well-known methodology in literature. It is developed since 1960s, but only in the last decades it is more considered, due to the increasing environmental consciousness. LCA is really useful, helping decision makers to select products or processes. However performing a full LCA analysis is very problematic, because it is resource and time intensive. Another great problem is represented by data, that can greatly impact the accuracy of the final results. Therefore it is important to weigh availability of data, necessary time to conduct the study and required financial resources against the projected benefits of LCA [1]. To pass these problems different simplified LCA methodologies are developed. The aim of simplifying LCA is to provide essentially the same results as a detailed LCA, followed by a simplified assessment, thus reducing significantly the expenses and time expended. It should still include all relevant aspects, but good explanations can, to some extent, replace resource demanding data collection and treatment. [2]

The aim of this paper is to realize a simplified LCA tool, driven by the extreme ease of use. Before to show it, in Section 2 a state of the art of simplified LCA is reported. The tool is presented in Section 3; finally Section 4 concludes the paper. 


\section{State of the Art}

Simplified LCA (S-LCA), also known as Streamlined LCA or Screening LCA, emerged as an efficient tool to evaluate the environmental attributes of a product, process, or service's life cycle [3]. The concepts of Screening, Simplified and Streamlined LCA are often mixed as they are all dealing with the attempt to simplify the LCA procedure [4].

In literature there are few definitions in which simplified LCA is as a simplified variety of detailed LCA conducted according to guidelines not in full compliance with the ISO 14040 standards and representative of studies that typically require from 1 to 20 person-days of work [5]. Hunt et al. refer to simplified methods as any measure or procedure taken to reduce the scope, cost, and effort required to conduct the LCA [6].

Goglio and Owende define simplified LCA as a method aimed to the identification of environmental hotspots or processes which the emissions of particular interest occur in the product / process life cycle [7]. In general the simplifying or streamlining can be viewed as a way of "cutting" whilst still meeting the study goal [8].

Nevertheless, the distinction between the Screening, Simplified and Streamlined LCA is not well-defined at all, it is up to the practitioner to define the methodology.

According with Fleischer et. al, data collection is the most time-consuming task in LCA, thus the most costly part is the life cycle inventory [9]. Also Christiansen et al. pointed out that effort should focus on the life cycle inventory analysis, which is typically the most time consuming phase, with the greatest potential for savings [10]. Considering that, there are different strategies for the simplification of the inventory analysis, depending on the goal and scope of the study (the specific application and decision to be supported), the required level of detail (information on single technological processes or aggregated entities), the acceptable level of uncertainty, and the available resources (time, human resources, know-how and budget).

To simplify LCA Rebitzer et al. describe three different types of approaches:

- Qualitative approaches: which are limited to a qualitative identification of the most environmentally critical stages or processes; making only a limited use of quantitative data;

- Semi-quantitative approaches: which are limited to the identification of the most environmentally critical stages or processes, making only a limited use of quantitative data;

- Quantitative approaches : applying numerical data, even though in a limited amount or in a quantity which is lower than that required by traditional LCA, often by restricted modeling of the product system by means of cut-off [11].

Pigosso and Sousa give a classification of the simplified LCA methods and tools identified by a systematic literature review. The authors report 27 simplified LCA methods and tools, many of which are of semi-quantitative approach [12].

The tool shown in this paper uses one of the semi-quantitative approach reported by Pigosso and Sousa: the Eco-Indicator 99. This approach is used by one of the most popular LCA software, SimaPro. 
The Eco-indicator of a material or process is a number that indicates the environmental impact of a material or process, based on data from a life cycle assessment. The unit of measure is the Eco-indicator point (Pt), but usually the milli-point ( $\mathrm{mPt})$ is adopted and used. The higher the indicator, the greater the environmental impact. The absolute value of the points is not very relevant and the main purpose is to compare relative differences between products or components. The standard Eco-indicator values can be regarded as dimensionless figures. Also, different types of Ecoindicator exist, depending on perspective and weighting. There are three types of perspective (egalitarian, hierarchist and individualist) and 4 types of weighting (average, egalitarian, hierarchist and individualist). Combining them different types of Eco-indicator are obtained and the most relevant are:

- The Hierarchist damage model and normalization with the Average weighting. $(\mathrm{H}, \mathrm{A})$

- The Egalitarian damage model and normalization with the Egalitarian weighting. $(\mathrm{E}, \mathrm{E})$

- The Individualist damage model and normalization with the Individualist weighting. $(\mathrm{I}, \mathrm{I})$

Eco-Indicator $99(\mathrm{H}, \mathrm{A})$ is considered to be the default version of the methodology while the other perspectives can be used in a robustness analysis.[13]

Therefore Eco-Indicator 99 (H,A) is used in the tool presented in this paper.

In summary, Simplified LCA (S-LCA) is used to reduce cost and time investment in the evaluation of environmental attributes of a product, process or service's life cycle. Many approaches exist in literature and they are classifiable in three categories: qualitative, semi-quantitative and quantitative. In particular Eco-Indicator 99, the methodology chosen, is highlighted.

\section{Tool Presentation}

In this section the tool is presented and a small example, based on the one in [13], is conducted. The idea of this tool, realized on Microsoft Excel, comes from the need to provide to the designers, not totally conscious of the environmental aspect, a very simple and fast tool to a first environmental analysis, in order to compare the different alternatives.

The file is organized in different spread sheets, grouped in four categories. First one is related to Eco-Indicator 99 (H,A) database, divided in: material, process, energy, transport and end of life. Database is necessary for the subsequent calculations and it gives the possibility to practitioners to access to more information about the indicators. For example, in Fig.1 table about production of ferro metals is reported. All database tables are composed by: the type of material, the value of the EcoIndicator, the indicator's unit of measure (MSU) and a brief description about the indicator. 


\begin{tabular}{|l|r|l|l|}
\hline Production of ferro metals & \multicolumn{2}{|l|}{} \\
\hline & Indicator & MSU & Description \\
\hline Cast iron & 240 & $\mathrm{mpt} / \mathrm{kg}$ & Casting iron with > 2\% carbon compound \\
\hline Converter steel & $94 \mathrm{mpt} / \mathrm{kg}$ & Block material containing only primary steel \\
\hline Electro steel & $24 \mathrm{mpt} / \mathrm{kg}$ & Block material containing only secondary scrap \\
\hline Steel & $86 \mathrm{mpt} / \mathrm{kg}$ & Block material containing $80 \%$ primary iron, $20 \% \mathrm{scrap}$ \\
\hline Steel high alloy & $910 \mathrm{mpt} / \mathrm{kg}$ & Block material containing $71 \%$ primary iron, $16 \% \mathrm{Cr}, 13 \% \mathrm{Ni}$ \\
\hline Steel low alloy & $110 \mathrm{mpt} / \mathrm{kg}$ & Block material containing $93 \%$ primary iron, $5 \%$ scrap, $1 \%$ alloy metals \\
\hline
\end{tabular}

Fig. 1. Example of Eco-Indicator 99 database: production of ferro materials

Database is taken from [13].

In the second category the designers can design the flow of product analysed, in order to understand the product life cycle.

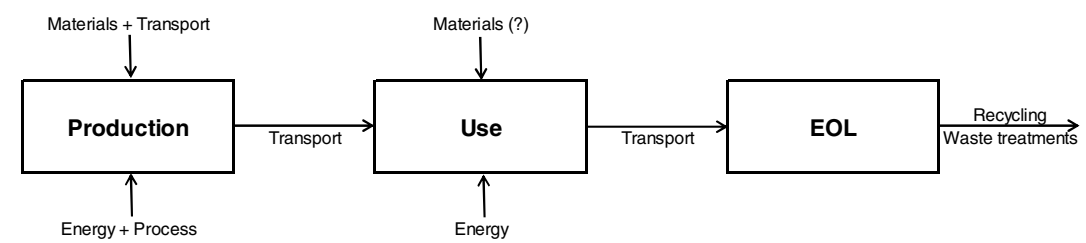

Fig. 2. Flow spread sheet

In the third category calculation is performed. In this category spread sheets are divided as in the database category (material, process, energy, transport and end of life).

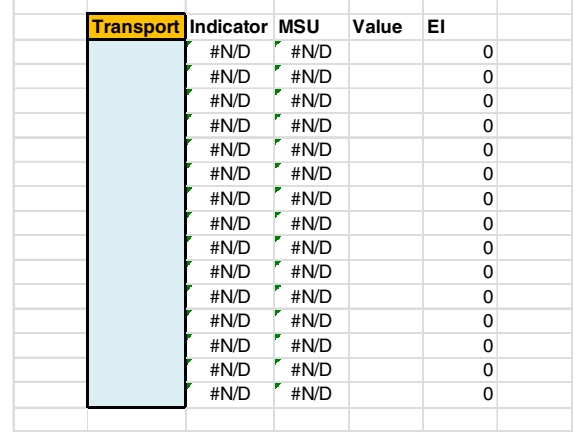

Fig. 3. Example of calculation spread sheet: transport

For example, in Fig.3 spread sheet to evaluate the environmental impact of transport is shown. In the light blue area there is a drop down menu where designers can choose the way of transport among all those in database. Choosing one of these Indicator and Unit of measure (MSU) get a value. Then designers should insert value (in this case usually is tonnes per kilometres). In EI column the calculation is performed, multiplying Value and Indicator.

Finally in the fourth category there is a report spread sheet, that shows a results summary.

Fig. 4 shows it. 


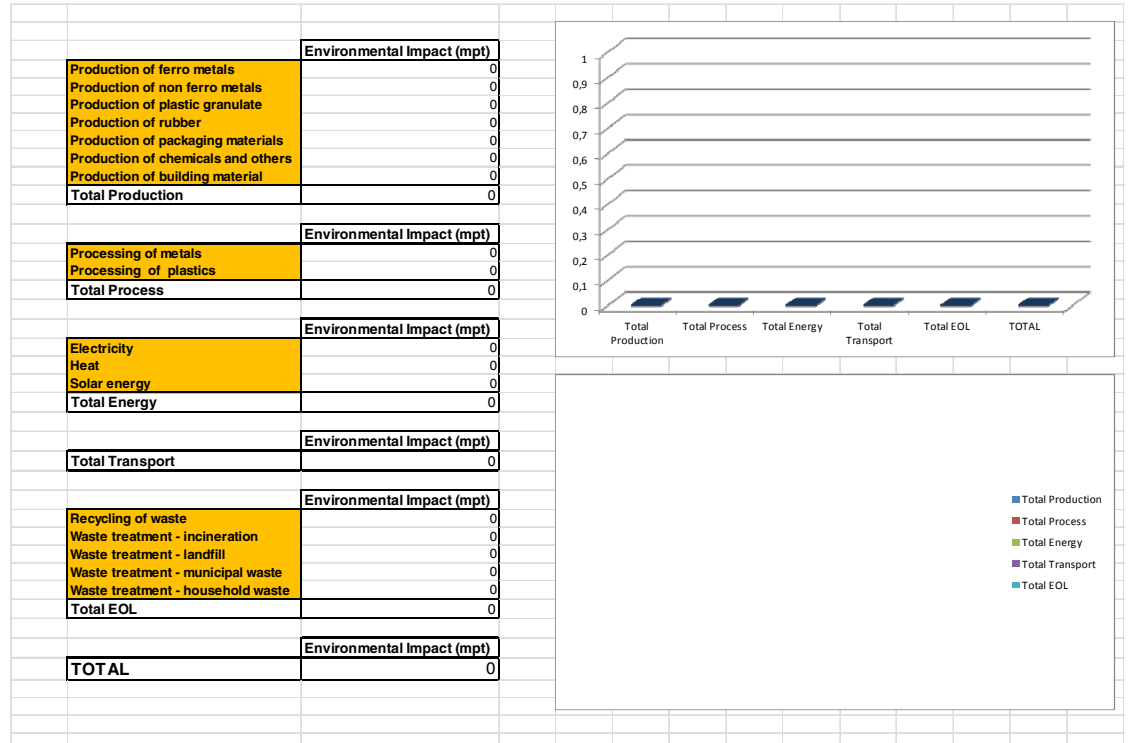

Fig. 4. Report spread sheet

Material, Process, Energy, Transport, EOL and Total environmental impacts are reported. Also a bar and a pie chart are realized to simplify the reading of the results.

To show how tool works, a sample from [13] is taken. The example is a simply analysis of a coffee machine. Some hypothesis are: the coffee machine is used for 5 years, making 5 cups of coffee, twice a day, and keeping it hot for half an hour after brewing. In the Fig. 5 you can see the flow of the coffee machine.

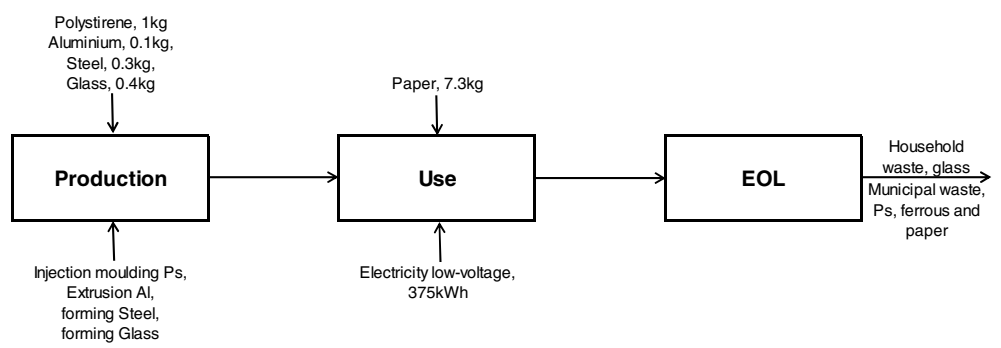

Fig. 5. Coffee machine flow

Materials and processes used to realize the coffee machine are considered, while in the Use phase filter papers and electricity to work the coffee machine are evaluated. Finally in EOL disposal of materials is taken into account.

After completing the flow, it is possible to perform the calculation. For example in Fig. 6 calculation of EOL is shown. 


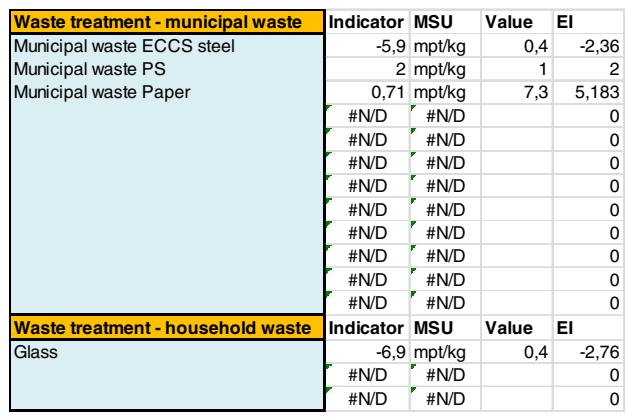

Fig. 6. Example of calculation: EOL

Results are reported in Fig. 7 (only the bar and pie chart are shown).

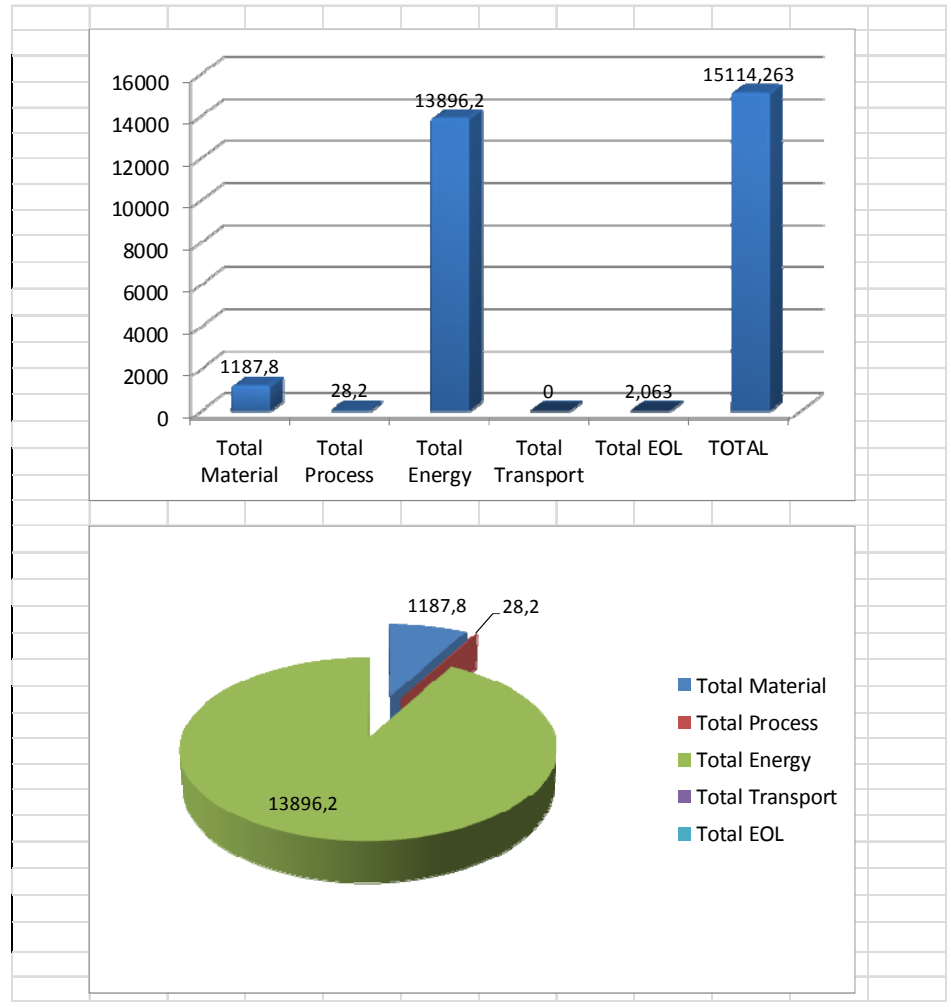

Fig. 7. Coffee machine report

As you can see from the graphs, the energy used is the major environmental impact of the coffee machine, in particular the electricity consumption. If the designers are able to reduce consumption they can significantly improve the sustainability of the product. 
In summary a tool is presented. It is based on Eco-Indicator and driven by the extreme ease of use. A small example is used to show how the tool work.

\section{Conclusion}

In this paper the aim is to realize a tool to evaluate environmental impacts of product / process / service. The tool doesn't perform a full LCA analysis, due to cost and time expensive. It conducts a simplified LCA analysis. Literature is explored and a huge approaches for simplified LCA are found. They are classifiable in three categories: qualitative, semi-quantitative and quantitative approach. For the tool presented in this paper Eco-Indicator methodology is chosen. Then the tool is explained and a small example is used to show how the tool works.

The objective is not to innovate or to revolutionize Life Cycle Assessment, but it is to realize a tool to a fast and simple evaluation of environmental impacts. Simplicity and speed are possible because the tool is based on a well known software (Excel), using one of the most simple S-LCA approach (Eco-Indicator).

Also, this tool could be part of a more general and complete framework about LCO (Life Cycle Optimization).

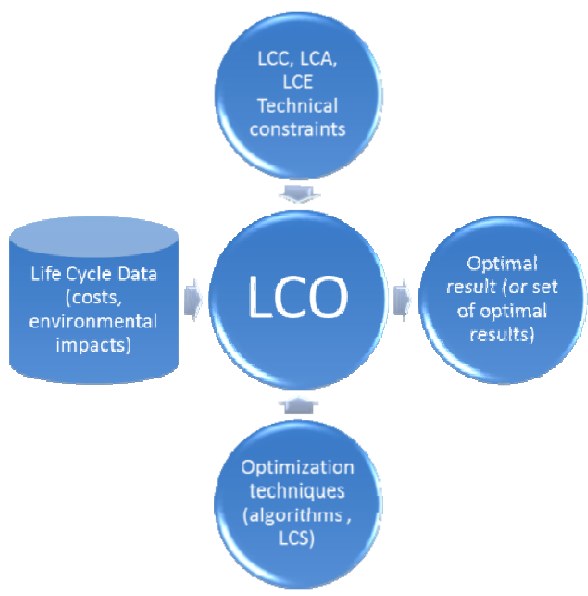

Fig. 8. General framework for Life Cycle Optimization

This framework considers three main elements for making a successful LCO: life cycle data, life cycle methodologies and optimization techniques. The presented tool will have the task of converting life cycle data related to environment (like used material, energy consumptions, etc.) in environmental impact. Future development will be the substitution of Eco-Indicator with something of more understandable like the Carbon Footprint.

Acknowledgments. This work was partly funded by the European Commission through the Linked Design Project (FoF-ICT-2011.7.4: Digital factories: Manufacturing design 
and product lifecycle management, http://www.linkeddesign.eu/). The authors wish to acknowledge their gratitude and appreciation to the rest of the project partners for their contributions during the development of various ideas and concepts presented in this paper.

\section{References}

1. Scientific Applications International Corporation: Life Cycle Assessment: principles and practice. In: Technical Report, 80 (2006)

2. Schmidt, A., Frydendal, J.: Methods for calculating the environmental benefits of 'green' products. In: Erdmenger, C. (ed.) Buying into the Environment: Experiences, Opportunities and Potential for Eco-Procurement. dk-TEKNIK Energy \& Environment, Denmark (2003)

3. Graedel, T.E., Saxton, E.: Improving the overall environmental performance of existing telecommunications facilities. The International Journal of Life Cycle Assessment 7(4), 219-224 (2002)

4. Widheden, J.: Methods for environmental assessment - useful to the DANTES project, Demonstrate and Asses New Tools for Environmental Sustainability. In: EU Life Environment Programme (2002)

5. Guinée, J.B., Gorrée, M., Heijungs, R., Huppes, G., Kleijn, R., Koning, A., de Oers, L., van Wegener Sleeswijk, A., Suh, S., Udo de Haes, H.A., Bruijn, H., de Duin, R., van Huijbregts, M.A.J.: Handbook on life cycle assessment. Operational guide to the ISO standards. I: LCA in perspective. IIa: Guide. IIb: Operational annex. III: Scientific background, p. 692. Kluwer Academic Publishers, Dordrecht (2002) ISBN 1-4020-0228-9

6. Hunt, R.G., Boguski, T.K., Weitz, K., Sharma, A.: Case studies examining LCA streamlining techniques. International Journal of Life Cycle Assessment 3, 36-42 (1998)

7. Goglio, P., Owende, P.M.: A screening LCA of short rotation coppice willow (Salix sp.) feedstock production system for small-scale electricity generation. Biosystems Engineering 103(3), 389-394 (2009)

8. Todd, J.A., Curran, M.A.: Streamlined life-cycle assessment: a final report from the SETAC North America Streamlined LCA Workgroup, SETAC (1999)

9. Fleischer, G., Gerner, K., Kunst, H., Lichtenvort, K., Rebitzer, G.: A semi-quantitative method for the impact assessment of emissions within a simplified life cycle assessment. The International Journal of Life Cycle Assessment 6(3), 149-156 (2001)

10. Christiansen, K., de Beaufort-Langeveld, A., van den Berg, N., Haydock, R., ten Houten, M., Kotaji, S., Oerlemans, E., Schmidt, W.P., Weidenhaupt, A., White, R.: Simplifying LCA: Just a cut? Final report SETAC-Europe LCA screening and streamlining working group. SETAC-Europe, Brussels (1997)

11. Rebitzer, G., Ekvall, T., Frischknecht, R., Hunkeler, D., Norris, G., Rydberg, T., Schmidt, W.P., Suh, S., Weidema, B.P., Pennington, D.W.: Life cycle assessment Part 1: Framework, goal and scope definition, inventory analysis, and applications. Environment International 30, 701-720 (2004)

12. Pigosso, D.C.A., Sousa, S.R.: Life Cycle Assessment (LCA): Discussion on Full-Scale and Simplified Assessments to Support the Product Development Process. In: 3rd International Workshop: Advances in Cleaner Production, São Paulo, Brazil, May 18-20 (2011)

13. PRé Consultants: Eco-indicator 99 - Manual for Designers. Published by: Ministry of Housing, Spatial Planning and the Environment, Technical report (2000) 